\title{
Theoretical Study of the Orientation Dependence of Charge-Transfer Excitations in Quinhydrones
}

Helmut Vogler

Max-Planck-Institut für Medizinische Forschung, Abteilung Organische Chemie, Jahnstraße 29, D-6900 Heidelberg 1

Z. Naturforsch. 38b, 1130-1135 (1983); received April 19, 1983

Charge-Transfer Excitations, Quinhydrones

The two longest wavelength electronic transitions of the quinhydrones 1 and the dependence of transition energies and intensities on the mutual orientation of hydroquinone and $p$-benzoquinone is studied within semiempirical $\pi$-theory. The results are in good agreement with the experimental UV-VIS spectra of closely related cyclophanequinhydrones. The study is extended to the yet unknown quadruple-layered systems 2 which consist of two quinhydrone moieties.

The UV-VIS spectra of the diastereomeric quinhydrones of the [2.2]- and [3.3]paracyclophane series $[1,2]$ demonstrate that the charge-transfer (CT) interaction depends significantly on the mutual orientation of the hydroquinone $(\mathrm{H})$ and $p$-benzoquinone $(\mathrm{Q})$ moiety. This could be expected in principle considering Mulliken's theory [3]. A first qualitative interpretation of the longest wavelength part of the electronic spectra of the intermolecular quinhydrones 1a and $\mathbf{1 b}$ (cf. Fig. 1) was given with the aid of simple Hückel theory [4]. An extension of that work seems to be appropriate since there the magnitude of the transanular interaction was treated as a further parameter and electron interaction was not explicitely taken into account in a Hückel approach although it might be crucial for a proper description of electronic excitations. Therefore we present in this communication a study of the lower excited singlet states of the quinhydrones $1(\alpha)$ (cf. Fig. 1) as a function of the geometry
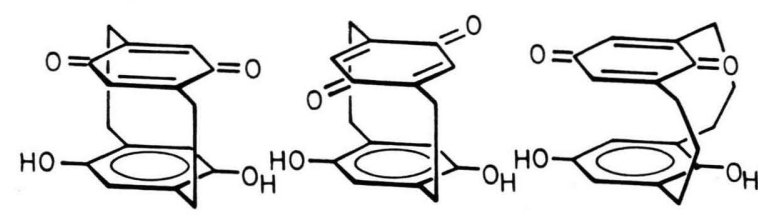

la

1b
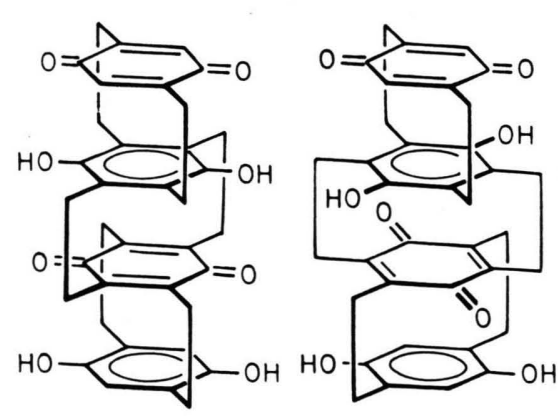

$2 b$

$2 a$

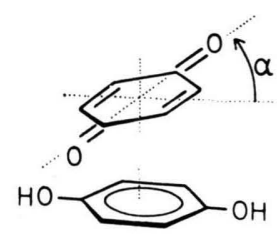

$1(\alpha)$

0340-5087/83/0900-1130/\$ 01.00/0

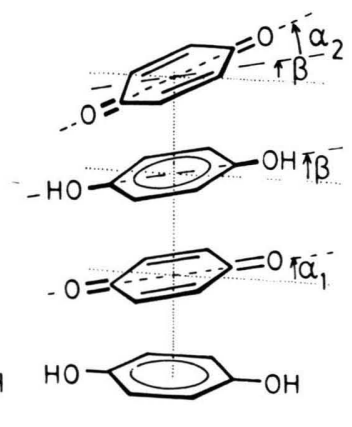

$2\left(\beta, \alpha_{1}, \alpha_{2}\right)$
Fig. 1. Some quinhydrone-cyclophanes and related models ( $\alpha$ is given in degrees). 
(orientation) parameter $\alpha .1(0)$ and $1(60)$ represent models for the cyclophanes $1 \mathrm{a}$ or $1 \mathrm{c}$ and $\mathbf{1 b}$, respectively.

In order to keep the analysis of the orientation dependence as simple as possible we will not take into account the deformations of the conjugated units, the inductive effect of the methylene groups, nor any through-bond interaction via the bridges. Since they are not crucial for the lower excited states (or are compensating each other) as can be concluded from the similarity of the long wavelength part of the UV-VIS spectra of [2.2]- and [3.3]paracyclophane-quinhydrones $[1,2]$. Furthermore Hückel-type calculations [5] using a new procedure for calculating the transanular resonance integrals [6] show that through-bond interaction has only a small effect on the frontier orbitals of quinhydrone systems quite in contrast to what was found with hydrocarbon-cyclophanes [7].

Our investigation is extended to the double quinhydrone systems $\mathbf{2}\left(\beta, \alpha_{1}, \alpha_{2}\right)$ where $\beta$ represents the mutual orientation of the two quinhydrone moieties $\mathrm{H}_{1} \mathrm{Q}_{1}$ and $\mathrm{H}_{2} \mathrm{Q}_{2}$ and $\alpha_{\mathrm{i}}$ that of $\mathrm{H}_{\mathrm{i}}$ and $\mathrm{Q}_{\mathrm{i}}$ within the quinhydrone $H_{i} Q_{i}$ (cf. Fig. 1). To our knowledge none of the correspondent quadruple-layered cyclophanes have been synthesized. $\mathbf{2 a}$ and $\mathbf{2 b}$ present examples for our models $2(0,0,0)$ and $2(60,120,120)$. Besides the terminal quinhydrone systems $\mathrm{H}_{1} \mathrm{Q}_{1}$ and $\mathrm{H}_{2} \mathrm{Q}_{2}$ in 2 we can recognize a third one formed by the inner conjugated subsystems $\mathrm{Q}_{1}$ and $\mathrm{H}_{2}$. Consequently several $\mathrm{CT}$ excitation types can be discriminated, i.e. $\mathrm{H}_{1} \rightarrow \mathrm{Q}_{1}, \mathrm{H}_{2} \rightarrow \mathrm{Q}_{2}, \mathrm{H}_{2} \rightarrow \mathrm{Q}_{1}$, and $\mathrm{H}_{1} \rightarrow \mathrm{Q}_{2}$, whereas only the $\mathrm{CT}$ excitation $\mathrm{H} \rightarrow \mathrm{Q}$ is possible with $\mathbf{1}(\alpha)$.

\section{Computational Procedure}

$A b$ initio procedures are hardly feasible for the extended systems studied in this communication and semiempirical all-valence schemes like CNDO/S [8] are unsuitable since CT transitions are calculated at far too high energies with respect to excitations within the conjugated subsystems [5]. On the other hand we have demonstrated [9] that $\pi$-theory is applicable to donor-acceptor systems with a sandwich geometry like $\mathbf{1}$.

Therefore in this communication we use a $\pi$-SCF procedure proposed by Younkin et al. [10]. The only change concerns the one-center electron repulsion integral for the quinone oxygen which has been increased by $2 \mathrm{eV}$ in order to obtain better transition energies for $\mathrm{Q}$. Possible $n \rightarrow \pi^{*}$ excitations are neglected in a $\pi$-theoretical approach, however, they are unimportant in the spectra of quinhydrones due to their low transition probabilities.

The excited singlet states are obtained by configuration interaction between 15 singly excited configurations (lowest in energy) $\varphi_{\mathbf{i}} \rightarrow \varphi_{\mathrm{k}}$ with an excitation from the occupied molecular orbital (MO) $\varphi_{\mathbf{i}}$ to the virtual MO $\varphi_{\mathrm{k}}$. The restriction to singly excited configurations is justified with the quinhydrone system but would be insufficient with much stronger donor/acceptor pairs than provided by $\mathrm{H} / \mathrm{Q}[9,11]$. The calculated transition energies differ from those of a full singly excited configuration interaction scheme by less than $0.1 \mathrm{eV}$ as has been checked by means of a self-consistent perturbational approach considering all possible singly excited configurations [12].

$3(4)$ configurations are enough for $\mathbf{1}(2)$ in order to obtain sufficient accuracy for the lower excited states studied in this paper. Extinctions have been calculated from the oscillator strengths $f$ utilizing the formula [13] $\log \varepsilon=\log f+4.5$. Means for analysing the excitations are given by the indices $\mathrm{w}_{i}^{\mathrm{R}}, \mathrm{x}^{\mathrm{R}}$ and $\mathrm{y}^{\mathrm{R}}$ [14] which indicate that $\mathrm{MO} \varphi_{\mathrm{i}}$ is localized by $\mathrm{w}_{\mathbf{i}}^{\mathbf{R} \%}$ on subsystem $\mathrm{R}$ and that the excitation starts by $\mathbf{x}_{\mathbf{R}} \%$ and ends up by $\mathbf{y}_{\mathbf{R}} \%$ in $\mathbf{R}$.

The calculations are performed using idealized geometries with coplanar conjugated systems with a separation of $R=2.95 \AA$ (mean distance of 6-rings in [2.2]paracyclophane [15]) and standard bond lengths [16].

\section{Results and Discussion}

Numerical results for quinhydrones 1 . In composite molecular systems like 1 one encounters a CT ('CT'1-effect' $[4,17]$, however, we try to avoid the word 'effect' here, see [18]) and such compounds can be called CT-systems in the ground state if there exists a donor and an acceptor. Consequently 1 is a CT-system with $\mathrm{H}$ as donor and $\mathrm{Q}$ as acceptor although the CT (here always understood as an electron transfer) $\mathrm{H} \rightarrow \mathrm{Q}$ is small. For example, the CT varies between 0.04 for $1(0)$ and 0.02 for $1(90)$. A larger CT in the ground state can be expected only with much stronger donor/acceptor pairs [11].

The numerical results of the configuration interaction calculations for $\mathbf{1}(\alpha)$ are given in Table I. 
Table I. Calculated singlet excitation energies $\mathrm{S}$, extinctions $\log \varepsilon, \mathrm{CT}$, and analysis of the excitations $\left(\mathrm{x}_{\mathrm{H}}, \mathrm{y}_{\mathrm{H}}\right.$, $\mathrm{x}_{\mathrm{Q}}, \mathrm{y}_{\mathrm{Q}}$ values, predominant configurations and localization of relevant MO's) of $\mathbf{1}(\alpha)$ as a function of $\alpha$.

\begin{tabular}{|c|c|c|c|c|c|c|c|c|c|c|c|}
\hline$\alpha$ & State & $\mathrm{S} / \mathrm{eV}$ & $\log \varepsilon^{\mathrm{a}}$ & $\mathrm{CT}^{\mathrm{b}}$ & $\mathrm{x}_{\mathrm{H}}$ & $\mathrm{y}_{\mathrm{H}}$ & $\mathrm{x}_{\mathrm{Q}}$ & $\mathrm{y}_{\mathrm{Q}}$ & $\varphi_{\mathrm{i}} \rightarrow \varphi_{\mathrm{k}}(\%)$ & $\mathrm{w}_{1}^{\mathrm{H}}$ & $w_{k}^{Q}$ \\
\hline \multirow[t]{2}{*}{0} & 1 & 2.46 & 3.4 & 0.99 & 97.5 & 2.2 & 2.5 & 97.8 & $9 \rightarrow 10(100)$ & 97 & 98 \\
\hline & 2 & 3.39 & - & 0.79 & 77.1 & 2.3 & 22.9 & 97.7 & $8 \rightarrow 10(93.0)$ & 82 & \\
\hline \multirow[t]{2}{*}{30} & 1 & 2.37 & 3.1 & 0.99 & 97.2 & 1.5 & 2.8 & 98.5 & $9 \rightarrow 10(99.5)$ & 97 & 98 \\
\hline & 2 & 3.49 & 2.6 & 0.81 & 80.0 & 1.6 & 20.0 & 98.4 & $8 \rightarrow 10(91.9)$ & 85 & \\
\hline \multirow[t]{2}{*}{60} & 1 & 2.27 & 2.3 & 0.97 & 96.7 & 1.0 & 3.3 & 99.0 & $9 \rightarrow 10(99.4)$ & 97 & 99 \\
\hline & 2 & 3.68 & 3.0 & 0.87 & 86.6 & 1.0 & 13.4 & 99.0 & $8 \rightarrow 10(92.1)$ & 93 & \\
\hline \multirow[t]{2}{*}{90} & 1 & 2.28 & - & 0.97 & 96.2 & 0.9 & 3.8 & 99.1 & $9 \rightarrow 10(99.4)$ & 97 & 99 \\
\hline & 2 & 3.86 & 3.2 & 0.98 & 97.7 & 0.9 & 2.3 & 99.1 & $8 \rightarrow 10(100)$ & 98 & \\
\hline
\end{tabular}

a Values $\log \varepsilon \leqq 0$ for weak or forbidden transitions are not given; b positive numbers indicate an electron transfer $\mathrm{H} \rightarrow \mathrm{Q}$.

The two lowest excited states are linear combinations (by more than $97 \%$ ) of the configurations $\varphi_{9} \rightarrow \varphi_{10}$ and $\varphi_{8} \rightarrow \varphi_{10}$ which are predominantly CT excitations (CE's).

The first transition in $\mathbf{1}(\alpha)$ is shifted towards lower excitation energy with increasing $\alpha$ whereas its intensity decreases. Just the opposite applies to the second transition. The results for $\mathbf{1}(\alpha)$ with $\alpha=0$ and $\alpha=60$ are in good agreement with the experimental UV-VIS spectra of $\mathbf{1 a}$ and $\mathbf{1 b}$ [1] (or the corresponding [3.3]paracyclophanes [2]) with respect to wavelengths and extinctions of these transitions, cf. Fig. 2. The occurence of an absorption at around $355 \mathrm{~nm}$ in the case of the pseudo-ortho $(o)$ isomer $\mathbf{1 b}$, which is absent in the pseudogeminal $(g)$ isomer $\mathbf{1} \mathbf{a}$, is nicely reproduced.

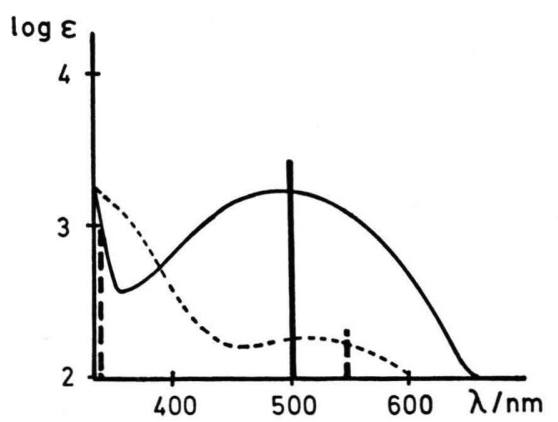

Fig. 2. Comparison of the calculated transitions for $\mathbf{1}(0)$ and $\mathbf{1}(60)$ with the experimental UV-VIS spectra of $1 \mathbf{a}(-)$ and $1 \mathbf{b}(--)$.

An excited state can be classified as a CT state or the excitation from the ground state as a CT transition [3] if the CT is larger than in the ground state $[4,17]$. Therefore the first two transitions of $\mathbf{1}(\alpha)$ are CT transitions. As long as $\alpha<90$ the CT of the second transition is smaller than that of the first one since it is weakly coupled to the excitation $\varphi_{6} \rightarrow \varphi_{10}$ being localized predominantly in $\mathrm{Q}$.

Rationalization of results. Without transanular resonance integrals all MO's $p$ i of the composite system $\mathbf{1}(\alpha)$ are localized either on the $\mathrm{H}$ - or the Q-subsystem, i.e. each MO $p \mathrm{i}$ can be associated uniquely with an $\mathrm{MO} \varphi_{\mathrm{j}}^{\mathrm{H}}$ or $\varphi_{\mathrm{j}}^{\mathrm{Q}}$ of isolated $\mathrm{H}$ or $\mathrm{Q}$. The excitations of interest in the quinhydrone system without transanular resonance integrals are the CE's $\varphi_{\mathrm{h}}^{\mathrm{H}} \rightarrow \varphi_{1}^{\mathrm{Q}}$ and $\varphi_{\mathrm{h}}^{\mathrm{H}} \rightarrow \varphi_{1}^{\mathrm{Q}}$ where $\varphi_{\mathrm{h}(1)}$ stands for the highest occupied (lowest virtual) MO. The excitation energy of a singly excited configuration $\varphi_{\mathrm{i}} \rightarrow \varphi_{\mathrm{k}}$ and its interaction with another configuration $\varphi_{\mathrm{j}} \rightarrow \varphi_{1}$ are given as [19] $\mathrm{S}_{\mathrm{ik}}=\Delta \varepsilon_{\mathrm{ik}}-\mathrm{J}_{\mathrm{ik}}+2 \mathrm{~K}_{\mathrm{ik}}$ and $\mathrm{W}_{\mathrm{ik}, \mathrm{j} 1}=2\left(\varphi_{\mathrm{i}} \varphi_{\mathrm{k}} \mid \varphi_{\mathrm{j}} \varphi_{1}\right)-\left(\varphi_{\mathrm{i}} \varphi_{\mathrm{j}} \mid \varphi_{\mathrm{k}} \varphi_{1}\right)$, where $\Delta \varepsilon_{\mathrm{ik}}=\varepsilon_{\mathrm{k}}-\varepsilon_{\mathrm{i}}$ is the difference of MO energies and $\left(\varphi_{\mathrm{i}} \varphi_{\mathrm{j}} \mid \varphi_{\mathrm{k}} \varphi_{1}\right)=\iint \varphi_{\mathrm{i}}(1) \varphi_{\mathrm{j}}(1) \varphi_{\mathrm{k}}(2) \varphi_{1}(2) \mathrm{r}_{12}^{-1} \mathrm{~d} \tau_{1} \mathrm{~d} \tau_{2}$. $J_{\mathrm{ik}}$ and $\mathbf{K}_{\mathrm{ik}}$ represent the Coulomb and exchange integral of MO's $\varphi_{\mathrm{i}}$ and $\varphi_{\mathrm{k}}$. The two CE's are either uncoupled (if $\alpha=0,90$ ) or their coupling is unimportant since the interaction integral $-\left(\varphi_{\mathrm{h}-1}^{\mathrm{H}} \varphi_{\mathrm{h}}^{\mathrm{H}} \mid \varphi_{1}^{\mathrm{Q}} \varphi_{1}^{\mathrm{Q}}\right)$ is numerically small due to the occurence of the overlap density $\varphi_{\mathrm{h}-1}^{\mathrm{H}} \varphi_{\mathrm{h}}^{\mathrm{H}}$ and the smaller intersubsystem electron repulsion integrals with respect to the intrasubsystem integrals.

A mixing of the MO's of $\mathrm{H}$ and $\mathrm{Q}$ is induced by the transanular resonance integrals. The admixture of $\varphi_{\mathrm{k}}^{\mathbf{Q}}$ to $\varphi_{\mathrm{i}}^{\mathrm{H}}$, for example, is only possible if both MO's belong to the same irreducible representation of the pointgroup of the composite system. The mixing will be significant if the orbital energy difference $\varepsilon_{\mathrm{k}}^{\mathrm{Q}}-\varepsilon_{\mathrm{i}}^{\mathrm{H}}$ of the MO's $\varphi_{\mathrm{i}}^{\mathrm{H}} / \varphi_{\mathrm{k}}^{\mathrm{Q}}$ is small and their transanular interaction is numerically large. The symmetry of the frontier orbitals of $\mathrm{H}$ and $\mathrm{Q}$ 


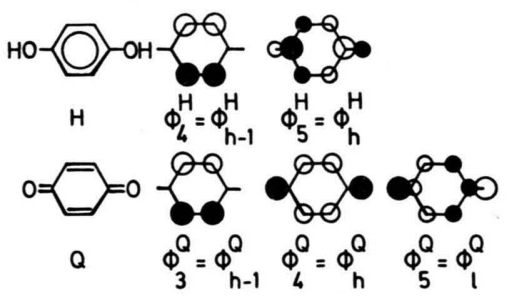

Fig. 3. Frontier orbitals $\varphi_{i}^{\mathrm{H}}$ of hydroquinone and $\varphi_{i}^{\mathbf{Q}}$ of $p$-benzoquinone.

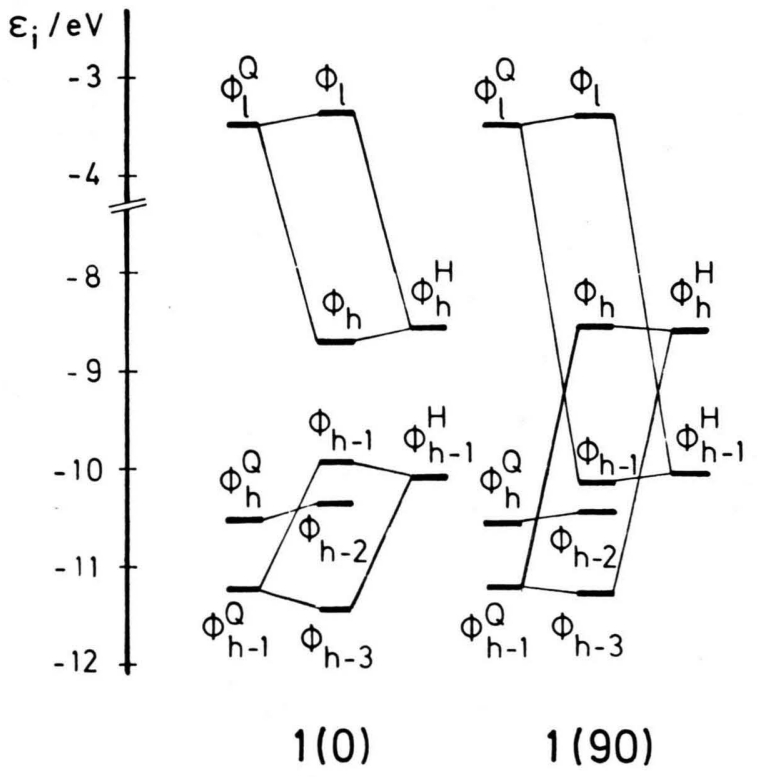

Fig. 4. Orbital energy scheme of $\mathbf{1}(0)$ and $\mathbf{1}(90)$ and their constituent subsystems hydroquinone and $p$-benzoquinone.

in a $g$-arrangement as in $\mathbf{1}(0)$ allows the interaction of $\varphi_{\mathrm{h}}^{\mathrm{H}} / \varphi_{1}^{\mathrm{Q}}$ as well as of $\varphi_{\mathrm{h}-1}^{\mathrm{Q}} / \varphi_{\mathrm{h}-1}^{\mathrm{H}}$ (cf. Fig. 3). Consequently the orbital energy scheme displayed in Fig. 4 is obtained with the MO's

$$
\begin{aligned}
& \varphi_{1}=\varphi_{10} \cong\left(1+\delta^{2}\right)^{-1 / 2}\left(\varphi_{1}^{\mathrm{Q}}-\delta \varphi_{\mathrm{h}}^{\mathrm{H}}\right) \\
& \varphi_{\mathrm{h}}=\varphi_{9} \cong\left(1+\delta^{2}\right)^{-1 / 2}\left(\varphi_{\mathrm{h}}^{\mathrm{H}}+\delta \varphi_{1}^{\mathrm{Q}}\right) \\
& \varphi_{\mathrm{h}-1}=\varphi_{8} \cong\left(1+\eta^{2}\right)^{-1 / 2}\left(\varphi_{\mathrm{h}-1}^{\mathrm{H}}+\eta \varphi_{\mathrm{h}-1}^{\mathrm{Q}}\right)
\end{aligned}
$$

In $1(90)$ only the interaction of the MO's $\varphi_{\mathrm{n}-1}^{\mathrm{H}} / \varphi_{1}^{\mathrm{Q}}$ and $\varphi_{\mathrm{h}}{ }_{\mathrm{Q}}^{\mathrm{q}} / \varphi_{\mathrm{h}}^{\mathrm{H}}$ is allowed leading to the orbital energy scheme of Fig. 4 with the MO's

$$
\begin{aligned}
& \varphi_{1}=\varphi_{10} \cong\left(1+v^{2}\right)^{-1 / 2}\left(\varphi_{1}^{\mathrm{Q}}-v \varphi_{\mathrm{h}-1}^{\mathrm{H}}\right) \\
& \varphi_{\mathrm{h}}=\varphi_{9} \cong\left(1+\tau^{2}\right)^{-1 / 2}\left(\varphi_{\mathrm{h}}^{\mathrm{H}}+\tau \varphi_{\mathrm{h}-1}^{\mathrm{Q}}\right) \\
& \varphi_{\mathrm{h}-1}=\varphi_{8} \cong\left(1+v^{2}\right)^{-1 / 2}\left(\varphi_{\mathrm{h}-1}^{\mathrm{H}}+v \varphi_{1}^{\mathrm{Q}}\right) .
\end{aligned}
$$

The transanular interactions of $\varphi_{\mathrm{h}}^{\mathrm{H}} / \varphi_{1}^{\mathrm{Q}}$ and $\varphi_{\mathrm{h}-1}^{\mathrm{Q}} / \varphi_{\mathrm{h}-1}^{\mathrm{H}}$ and thus the magnitude of $|\delta|$ and $|\eta|$ become smaller with enhanced $\alpha$ whereas the interactions $\varphi_{\mathrm{n}-1}^{\mathrm{H}} / \varphi_{1}^{\mathrm{Q}}$ and $\varphi_{\mathrm{h}-1}^{\mathrm{Q}} / \varphi_{\mathrm{h}}^{\mathrm{H}}$ and hence $|v|$ and $|\tau|$ increase. This can be deduced from Fig. 3 by considering (for $\alpha=0$ and $a=60$ ) the sum of the products of the MO coefficients at carbon atoms in $\mathrm{H}$ and $\mathrm{Q}$ which are one upon another in $\mathbf{1}(\alpha)$. This sum is a measure for the magnitude of the transanular interaction in such systems due to the numerical nature of the transanular resonance integrals [6].

The coupling of the CE's $\varphi_{9} \rightarrow \varphi_{10}$ and $\varphi_{8} \rightarrow \varphi_{10}$ is insignificant even with finite transanular interaction. As can be seen from Fig. 4 the MO energies $\varepsilon_{i}$ and consequently the MO energy differences $\Delta \varepsilon_{\mathrm{ik}}$ vary with $\alpha$. According to the interaction schemes it is obvious that $\Delta \varepsilon_{910}$ should become smaller and $\Delta \varepsilon_{810}$ should increase with enhanced $\alpha$. This is confirmed by the calculated $\Delta \varepsilon_{910}$ and $\Delta \varepsilon_{810}$ values given in Table II for $\mathbf{1}(\alpha)$ as a function of $\alpha$. Only from $\alpha=60$ to $\alpha=90$ do we not find a lowering of $\Delta \varepsilon_{910}$ which derives from the increase of $\Delta \varepsilon_{910}$ already without transanular resonance integrals (cf. Table II) caused by changes in the diagonal part of the $\pi$-Hartree-Fock operator due to the non-uniform charge distribution in $\mathrm{H}$ and $\mathrm{Q}$. The

Table II. Orbital energy differences $\Delta \varepsilon_{\mathrm{ik}}=\varepsilon_{\mathrm{k}}-\varepsilon_{\mathrm{i}}$, integrals $-\mathrm{J}_{\mathrm{ik}}+2 \mathrm{~K}_{\mathrm{ik}}$, excitation energies $\mathrm{S}_{\mathrm{ik}}$, and extinctions $\log \varepsilon_{\mathrm{ik}}$ for the $\varphi_{9} \rightarrow \varphi_{10}$ and $\varphi_{8} \rightarrow \varphi_{10}$ excitations of $\mathbf{1}(\alpha)$ as a function of $\alpha$. All energy values are given in units of $\mathrm{eV}$.

\begin{tabular}{cllllllll}
\hline & $\varphi_{9} \rightarrow \varphi_{10}$ & \multicolumn{5}{c}{$\varphi_{8} \rightarrow \varphi_{10}$} \\
\hline & $\Delta \varepsilon_{i \mathrm{k}}$ & $-J_{\mathrm{ik}}+2 \mathrm{~K}_{\mathrm{ik}}$ & $\mathrm{S}_{\mathrm{ik}}$ & $\log \varepsilon_{\mathrm{ik}} \mathrm{b}$ & $\Delta \varepsilon_{\mathrm{ik}}$ & $-\mathrm{J}_{\mathrm{ik}}+2 \mathrm{~K}_{\mathrm{ik}}$ & $\mathrm{S}_{\mathrm{ik}}$ & $\log \varepsilon_{\mathrm{ik}} \mathrm{b}$ \\
0 & 5.28 & -2.83 & 2.46 & 3.4 & 6.56 & -3.08 & 3.47 & - \\
30 & 5.24 & -2.86 & 2.38 & 3.1 & 6.59 & -3.04 & 3.56 & 2.6 \\
60 & 5.20 & -2.92 & 2.29 & 2.4 & 6.67 & -2.95 & 3.73 & 3.0 \\
90 & 5.21 & -2.93 & 2.29 & - & 6.75 & -2.89 & 3.86 & 3.2 \\
$0^{\mathrm{a}}$ & 5.11 & -2.94 & 2.18 & - & 6.66 & -2.93 & 3.74 & - \\
$90^{\mathrm{a}}$ & 5.21 & -2.89 & 2.33 & - & 6.69 & -2.95 & 3.74 & - \\
\hline
\end{tabular}

a Without transanular resonance integrals; ${ }^{\mathrm{b}}$ values $\log \varepsilon \leqq 0$ are not given. 
first and second singlet excitation energy $\mathrm{S}$ of $\mathbf{1}(\alpha)$ is governed by $S_{910}$ and $S_{810}$, respectively. These $S_{i k}$ values are proportional to the corresponding $\Delta \varepsilon_{\mathrm{ik}}$, however, the changes of $\mathrm{S}_{\mathrm{ik}}$ are greater than those of $\Delta \varepsilon_{\mathrm{ik}}$ since the $-\mathrm{J}_{\mathrm{ik}}+2 \mathrm{~K}_{\mathrm{ik}}$ terms are proportional to $\Delta \varepsilon_{\mathrm{ik}}$ as well, $c f$. Table II, i.e. $-\mathrm{J}_{910}+2 \mathrm{~K}_{910}$ decreases whereas $-J_{810}+2 K_{810}$ increases with enlarged $\alpha$. This behaviour derives straighforwardly from the covalent mixing of MO's in 1 $(\alpha)$. Using the MO's given in eqs. (1) and (2) we obtain $-J_{910}+2 \mathrm{~K}_{910}=-\mathrm{J}_{\mathrm{hl}}^{\mathrm{HQ}}+\delta^{2} \mathrm{C}_{\mathrm{h}}$ for $\mathbf{1}(0)$ and $-\mathrm{J}_{810}+2 \mathrm{~K}_{810}=-\mathrm{J}_{\mathrm{h}-11}^{\mathrm{HQ}}+v^{2} \mathrm{C}_{\mathrm{h}-1}$ for $\mathbf{1}(90)$ where $\mathrm{C}_{\mathrm{i}}=\mathrm{J}_{\mathrm{ii}}^{\mathrm{HH}}+\mathrm{J}_{11}^{\mathrm{QQ}}-2 \mathrm{~J}_{\mathrm{i} 1}^{\mathrm{HQ}} \geqq 0$. Since $\delta^{2}$ decreases and $v^{2}$ increases with enhanced $\alpha-\mathrm{J}_{910}+2 \mathrm{~K}_{910}$ reaches its maximum for $\mathbf{1}(0)$ and $-\mathrm{J}_{810}+2 \mathrm{~K}_{810}$ for $\mathbf{1}(90)$, $c f$. Table II.

The extinction coefficient $\varepsilon_{\mathrm{ik}}$ of the excitation $\varphi_{\mathrm{i}} \rightarrow \varphi_{\mathrm{k}}$ is proportional to the integral $\left|\left\langle\varphi_{\mathrm{i}}|\overrightarrow{\mathrm{r}}| \varphi_{\mathrm{k}}\right\rangle\right|$, where in our context only the z-component of $\vec{r}$ is of interest. Without any transanular interaction CE's $\varphi_{\mathrm{i}}^{\mathrm{H}} \rightarrow \varphi_{\mathrm{k}}^{\mathrm{Q}}$ are characterized due to vanishing intensities since $\left|\left\langle\varphi_{\mathrm{i}}^{\mathrm{H}}|\mathbf{z}| \varphi_{\mathrm{k}}^{\mathbf{Q}}\right\rangle\right|=\mathbf{R}\left|\left\langle\varphi_{\mathrm{i}}^{\mathrm{H}} \mid \varphi_{\mathrm{k}}^{\mathbf{Q}}\right\rangle\right|=0$ within the zero-differential-overlap approximation. Nonvanishing extinction coefficients are obtained for CE's only if covalent mixing of the MO's of isolated $\mathrm{H}$ and $\mathrm{Q}$ is induced by transanular resonance integrals. Using the MO's given by eqs. (1) and (2) we obtain $\varepsilon_{910} \sim|\delta| R$ and $\varepsilon_{810}=0$ for $1(0)$ and $\varepsilon_{910}=0$ and $\varepsilon_{810} \sim|v| \mathbf{R}$ for $\mathbf{1}(90)$. Consequently the intensity of the $\mathrm{CE} \varphi_{9} \rightarrow \varphi_{10}$ decreases with enhanced $\alpha$ whereas that of the $\mathrm{CE} \varphi_{8} \rightarrow \varphi_{10}$ increases, $c f$. Table II, thus offering a simple explanation for the striking differences in intensity of first and second CT transition of $\mathbf{1 a}$ and $\mathbf{1 b}$ [1].
Double quinhydrone systems $\mathbf{2}$. The double quinhydrone systems 2 with the arrangement $\mathrm{H}_{1} \mathrm{Q}_{1} \mathrm{H}_{2} \mathrm{Q}_{2}$ of $\mathrm{H}$ and $\mathrm{Q}$ moieties can be classified with respect to the mutual orientations of $\mathrm{H}$ and $\mathrm{Q}$ in $\mathrm{H}_{1} \mathrm{Q}_{1}, \mathrm{H}_{2} \mathrm{Q}_{1}$, and $\mathrm{H}_{2} \mathrm{Q}_{2}$ analogously to $\mathbf{1}(0)$ and $\mathbf{1}(60)$, cf. Table III. The isomers of $\mathbf{2}$ are CT systems in the ground state with $\mathrm{H}_{1}$ and $\mathrm{H}_{2}$ as donors and $\mathrm{Q}_{1}$ and $\mathrm{Q}_{2}$ as acceptors. With 2 it is no longer possible to elucidate the CT paths, instead only the net charges $q_{R}$ (negative $\mathrm{q}_{\mathrm{R}}$ indicates loss of electron density) or the total $\mathrm{CT}$ in the whole system defined as $-\left(\mathrm{q}_{\mathrm{H}_{1}}+\mathrm{q}_{\mathrm{H}_{2}}\right)=\mathrm{q}_{\mathrm{Q}_{1}}+\mathrm{q}_{\mathrm{Q}_{2}}$ can be given. The net charges are numerically small in the ground state similar as with 1, e.g. $\mathrm{q}_{\mathrm{H}_{1}}=-\mathrm{q}_{\mathrm{Q}_{2}}=-0.04, \mathrm{q}_{\mathrm{H}_{2}}=-\mathrm{q}_{\mathrm{Q}_{1}}=-0.07$ for the $g g g$-isomer $2(0,0,0)$ and they tend to become numerically smaller with increasing $o$-orientation, the corresponding values for the ooo-isomer are -0.01 and -0.03 . The total CT is slightly larger with 2 than with 1.

The transition energies and the associated extinctions for the three lowest excited singlet states of 2 are given in Table III. They are CT states since the net charges are numerically larger than in the ground state. The total CT amounts to values between 0.97 and 1.06. The excitation energies of the three states lie in a small interval ranging from $0.1 \mathrm{eV}(e . g .2(60,0,0))$ to $0.32 \mathrm{eV}(e . g . \mathbf{2}(60,60,0))$ and most likely in an experimental UV-VIS spectrum they will not be discernible. The lowest excitation energy is shifted to longer wavelength with increasing $o$-orientations, the same applies to some extent also to the other two transitions. The longest wavelength absorption of the $g g g$-isomer $\mathbf{2}(0,0,0)$ (model for 2a) should be slightly to the red compared

Table III. Calculated excitation energies $\mathrm{S}$ (in units of $\mathrm{eV}$ ) and extinctions $\log \varepsilon$ of the three lowest singlet states of $2\left(\beta, \alpha_{1}, \alpha_{2}\right)$.

\begin{tabular}{|c|c|c|c|c|c|c|c|}
\hline$\left(\beta, \alpha_{1}, \alpha_{2}\right)$ & Orientation ${ }^{\mathrm{a}}$ & $\begin{array}{l}\text { State } \\
1 \\
\text { S }\end{array}$ & $\log \varepsilon$ & $\begin{array}{l}2 \\
\mathrm{~S}\end{array}$ & $\log \varepsilon^{b}$ & $\begin{array}{l}3 \\
\mathrm{~S}\end{array}$ & $\log \varepsilon$ \\
\hline $\begin{array}{l}(0,0,0) \\
(0,0,60) \\
(60,0,0) \\
(60,60,0) \\
(60,120,0) \\
(60,60,120) \\
(60,0,120) \\
(60,120,120)\end{array}$ & $\begin{array}{l}\text { ggg } \\
\text { ggo } \\
\text { gog } \\
\text { ogg } \\
\text { oog } \\
\text { ogo } \\
\text { goo } \\
\text { ooo }\end{array}$ & $\begin{array}{l}2.42 \\
2.33 \\
2.40 \\
2.31 \\
2.27 \\
2.25 \\
2.28 \\
2.25\end{array}$ & $\begin{array}{l}3.8 \\
2.8 \\
3.3 \\
2.6 \\
2.7 \\
2.5 \\
2.5 \\
2.3\end{array}$ & $\begin{array}{l}2.52 \\
2.47 \\
2.47 \\
2.47 \\
2.46 \\
2.33 \\
2.38 \\
2.31\end{array}$ & $\begin{array}{l}- \\
3.6 \\
3.4 \\
3.6 \\
3.2 \\
2.6 \\
2.4 \\
2.6\end{array}$ & $\begin{array}{l}2.64 \\
2.60 \\
2.50 \\
2.63 \\
2.51 \\
2.56 \\
2.51 \\
2.46\end{array}$ & $\begin{array}{l}1.7 \\
2.2 \\
2.6 \\
2.4 \\
2.9 \\
3.3 \\
3.4 \\
1.3\end{array}$ \\
\hline
\end{tabular}

\footnotetext{
a Mutual orientation of $\mathrm{H}$ and $\mathrm{Q}$ given in the order $\mathrm{H}_{1} \mathrm{Q}_{1}, \mathrm{H}_{2} \mathrm{Q}_{1}, \mathrm{H}_{2} \mathrm{Q}_{2}$ as $g$ (pseudogeminal) or o (pseudo-ortho);
} b values $\log \varepsilon \leqq 0$ are not given. 
with $\mathbf{1}(0)$ and the same is valid for the ooo-isomer $\mathbf{2}(60,120,120)$ (model for $\mathbf{2 b}$ ) with respect to $\mathbf{1}(60)$. Similarly, in the case of $\mathbf{1}(\alpha)$ increasing $o$-orientations decrease the intensity of the first transition. The orientation dependence of the longest wavelength absorption band, which should be well separated from the next absorption bands since the fourth excitation is higher in energy by at least $0.6 \mathrm{eV}$, will show up mainly in small shifts of the band maximum and possibly the band shape.

The investigated three excited states are nearly exclusively linear combinations of the four configurations $\varphi_{17} \rightarrow \varphi_{19}, \varphi_{17} \rightarrow \varphi_{20}, \varphi_{18} \rightarrow \varphi_{20}$, and $\varphi_{18} \rightarrow \varphi_{19}$. They are CE's since $\varphi_{17}$ and $\varphi_{18}$ are mainly localized on $\mathrm{H}_{1}$ or $\mathrm{H}_{2}$ whereas $\varphi_{19}$ and $\varphi_{20}$ on $\mathrm{Q}_{1}$ or $\mathrm{Q}_{2}$. The first three configurations correspond predominantly to $C E$ 's $\mathrm{H}_{1} \rightarrow \mathrm{Q}_{1}, \mathrm{H}_{2} \rightarrow \mathrm{Q}_{2}$, and $\mathrm{H}_{2} \rightarrow \mathrm{Q}_{1}$ which are characterized due to similar excitation energies, e.g. with $2(0,0,0)$ they differ by less than $0.13 \mathrm{eV}$. The configuration $\varphi_{18} \rightarrow \varphi_{19}$ describes predominantly a $\mathrm{CE} \mathrm{H}_{1} \rightarrow \mathrm{Q}_{2}$ being higher in energy by about $0.5 \mathrm{eV}$ on the average due to the large $\mathrm{H}_{1} \rightarrow \mathrm{Q}_{2}$ separation.

\section{Conclusion}

In this communication we studied the dependence of the CT excitations of the quinhydrone systems $\mathbf{1}(\alpha)$ as a function of the orientation parameter $\alpha$. A satisfactory explanation could be given for the characteristic differences in the longest wavelength part of the UV-VIS spectra of $1 \mathrm{a}$ and $\mathbf{1 b}$ [1].

The excitation energies $S_{i k}$ of the two CE's with lowest energy proved to be proportional to the corresponding MO energy differences $\Delta \varepsilon_{\mathbf{i k}}$. Furthermore these CE's remain almost uncoupled and dominate the wave-functions of the two lowest excited singlet states. Therefore our simple Hückel type calculations [4] describe properly the aforementioned differences between $1 \mathrm{a}$ and $\mathbf{1 b}$. For $0 \leqq \alpha \leqq 60$ the Hückel excitation energies obtained with a new approach for the transanular resonance integrals [6] correlate perfectly with the $S_{i k}$ values calculated in this work. A total break-down of the Hückel approach for calculating excitation energies is encountered with systems like $\mathbf{2}$ where the states are dominated by important (nearly first order) configuration interaction. Furthermore the Hückel theory is unable to discriminate energetically between the CE's $\mathrm{H}_{1} \rightarrow \mathrm{Q}_{1}, \mathrm{H}_{2} \rightarrow \mathrm{Q}_{2}$ or $\mathrm{H}_{2} \rightarrow \mathrm{Q}_{1}$ and the $\mathrm{CE} \mathrm{H}_{1} \rightarrow \mathrm{Q}_{2}$.

Finally our analysis of the electronic structure of quinhydrones revealed that the frontier orbitals are mainly localized on either $\mathrm{H}$ or $\mathrm{Q}$ even with nonvanishing transanular resonance integrals. Therefore through-bond interaction is unimportant for transitions which are dominated by CE's or local excitations restricted to these frontier orbitals or generally to those orbitals which are not considerably delocalized over the whole quinhydrone system.

The author wishes to thank Professor H. A. Staab for his interest in this research and for providing the UV-VIS spectra of $\mathbf{1 a}$ and $\mathbf{1 b}$. This work was supported by the Deutsche Forschungsgemeinschaft and the Fonds der Chemie. The calculations were carried out on the IBM 370/168 computer of the Universitätsrechenzentrum Heidelberg.
[1] H. A. Staab and W. Rebafka, Chem. Ber. 110, 3333 (1977).

[2] H. A. Staab and C. P. Herz, Angew. Chem. 89, 839 (1977).

[3] R. S. Mulliken and W. B. Person, Molecular Complexes. A Lecture and Reprint Volume, Wiley Interscience, New York 1969.

[4] H. Vogler, G. Ege, and H. A. Staab, Tetrahedron 31, 2441 (1975).

[5] H. Vogler, unpublished results.

[6] H. Vogler, Theor. Chim. Acta 60, 65 (1981).

[7] B. Kovač, M. Mohraz, E. Heilbronner, V. Boekelheide, and H. Hopf, J. Am. Chem. Soc. 102, 2314 (1980).

[8] J. Del Bene and H. H. Jaffé, J. Chem. Phys. 48, 1807, 4050 (1968); O. Chalvet, H. H. Jaffé, and J. Jacques, QCPE Newslett. 71, 7 (1980).

[9] H. Vogler, and M. C. Böhm, Mol. Phys. (in press).

[10] J. M. Younkin, L. J. Smith, and R. N. Compton, Theor. Chim. Acta 41, 157 (1976).
[11] H. Vogler, Croat. Chem. Acta 56, 297 (1983).

[12] H. Baumann, J. Am. Chem. Soc. 100, 7196 (1978).

[13] J. Pancì̌, I. Matoušek, and R. Zahradnìk, Coll. Czech. Chem. Commun. 38, 3039 (1973).

[14] J. Casado, J. Peleteiro, and M. A. Rios, Chem. Phys. Lett. 62, 349 (1979).

[15] H. Hope, J. Bernstein, and K. N. Trueblood, Acta Crystallogr. B 28, 1733 (1972).

[16] J. A. Pople and D. L. Beveridge, Approximate Molecular Orbital Theory, p. 111, McGraw-Hill, New York 1970.

[17] R. Brüggemann and J. Voitländer, Theor. Chim. Acta 34, 301 (1974).

[18] A. D. Liehr, Z. Naturforsch. 16a, 641 (1961). See also: G. Ludwig, Einführung in die Grundlagen der Theoretischen Physik, p. 88, Vieweg, Braunschweig 1976.

[19] J. A. Pople, Proc. Phys. Soc. A 68, 81 (1955). 